\title{
Exposure to chemical components of fine particulate matter and ozone, and placenta-mediated pregnancy complications in Tokyo: a register-based study
}

\author{
Takehiro Michikawa $\mathbb{1}^{1}$ - Seiichi Morokuma ${ }^{2}$ - Shin Yamazaki ${ }^{3}$. Akinori Takami ${ }^{4}$ - Seiji Sugata ${ }^{4}$ Ayako Yoshino ${ }^{4}$. \\ Yuki Takeda ${ }^{1} \cdot K_{\text {Kazushige Nakahara }}^{5} \cdot$ Shinji Saito $^{6} \cdot$ Junya Hoshi $^{6} \cdot$ Kiyoko Kato $^{5} \cdot$ Hiroshi Nitta $^{3} \cdot$ Yuji Nishiwaki $^{1}$
}

Received: 12 August 2020 / Revised: 1 January 2021 / Accepted: 21 January 2021 / Published online: 18 February 2021

(c) The Author(s) 2021. This article is published with open access

\begin{abstract}
Background Maternal exposure to fine particulate matter $\left(\mathrm{PM}_{2.5}\right)$ was associated with pregnancy complications. However, we still lack comprehensive evidence regarding which specific chemical components of $\mathrm{PM}_{2.5}$ are more harmful for maternal and foetal health.

Objective We focused on exposure over the first trimester (0-13 weeks of gestation), which includes the early placentation period, and investigated whether $\mathrm{PM}_{2.5}$ and its components were associated with placenta-mediated pregnancy complications (combined outcome of small for gestational age, preeclampsia, placental abruption, and stillbirth).

Methods From 2013 to 2015, we obtained information, from the Japan Perinatal Registry Network database, on 83,454 women who delivered singleton infants within 23 Tokyo wards $\left(\approx 627 \mathrm{~km}^{2}\right)$. Using daily filter sampling of $\mathrm{PM}_{2.5}$ at one monitoring location, we analysed carbon and ion components, and assigned the first trimester average of the respective pollutant concentrations to each woman.

Results The ORs of placenta-mediated pregnancy complications were $1.14(95 \% \mathrm{CI}=1.08-1.22) \mathrm{per} 0.51 \mu \mathrm{g} / \mathrm{m}^{3}$ (interquartile range) increase of organic carbon and $1.11(1.03-1.18)$ per $0.06 \mu \mathrm{g} / \mathrm{m}^{3}$ increase of sodium. Organic carbon was also associated with four individual complications. There was no association between ozone and outcome.

Significance There were specific components of $\mathrm{PM}_{2.5}$ that have adverse effects on maternal and foetal health.
\end{abstract}

Keywords Particulate matter $\cdot$ Chemical component $\cdot$ Placenta-mediated pregnancy complications $\cdot$ Placentation

Supplementary information The online version contains supplementary material available at https://doi.org/10.1038/s41370021-00299-4.

Takehiro Michikawa

takehiro.michikawa@med.toho-u.ac.jp

1 Department of Environmental and Occupational Health, School of Medicine, Toho University, Ota-ku, Tokyo, Japan

2 Department of Health Sciences, Graduate School of Medical Sciences, Kyushu University, Higashi-ku, Fukuoka, Japan

3 Centre for Health and Environmental Risk Research, National Institute for Environmental Studies, Tsukuba, Ibaraki, Japan

4 Centre for Regional Environmental Research, National Institute for Environmental Studies, Tsukuba, Ibaraki, Japan

5 Department of Obstetrics and Gynaecology, Graduate School of Medical Sciences, Kyushu University, Higashi-ku, Fukuoka, Japan

6 Tokyo Metropolitan Research Institute for Environmental Protection, Koto-ku, Tokyo, Japan

\section{Introduction}

Exposure to fine particulate matter $\left(\mathrm{PM}_{2.5}\right)$ in the ambient atmosphere has adverse health effects across all generations [1]. Women of reproductive age are not exceptions. There is evidence that exposure to $\mathrm{PM}_{2.5}$ during pregnancy is associated with obstetric complications that threaten the health of pregnant mothers, such as hypertensive disorders of pregnancy (including preeclampsia) and placental abruption [2-5]. In addition, maternal exposure to $\mathrm{PM}_{2.5}$ appears to have harmful effects on the next generation; for example, $\mathrm{PM}_{2.5}$ exposure during pregnancy was associated with foetal growth restriction that resulted in the birth of small for gestational age (SGA) children [6, 7], and was linked to the occurrence of stillbirths [8]. Although the accumulating findings suggest that total $\mathrm{PM}_{2.5}$ (general mixture) influences maternal and foetal health, we still lack comprehensive evidence regarding which specific chemical 
components of $\mathrm{PM}_{2.5}$ are more harmful for their health [9]. Thus, understanding the association between individual $\mathrm{PM}_{2.5}$ components and perinatal health may provide information of value to policy making for environmental health.

The placenta is a temporal organ, and normal placentation is absolutely essential for foetal development and growth, while also contributing to maternal health [10]. Conversely, abnormal placentation during the first trimester is related to adverse maternal and foetal conditions called placentamediated pregnancy complications, including SGA, preeclampsia, placental abruption, and stillbirth [11-13]. As aforementioned, each of these four complications has been reported to be individually associated with maternal exposure to $\mathrm{PM}_{2.5}[2,5-8]$. Therefore, in the present study, we focused on $\mathrm{PM}_{2.5}$ exposure over the first trimester, which is an important period of placentation, and investigated the association with placenta-mediated pregnancy complications, with the aim of elucidating the relationship between $\mathrm{PM}_{2.5}$ exposure and placental toxicity, and seeking a pathogenic foundation common to individual complications. In light of the fact that $\mathrm{PM}_{2.5}$ may be a common risk factor for four individual complications, few studies have examined the association between $\mathrm{PM}_{2.5}$ exposure and placentamediated pregnancy complications as a composite outcome. Also, it seems likely that ozone is a risk factor for placentamediated pregnancy complications, because the potential maternal and foetal health effects of ozone exposure were indicated [14].

In sum, the aim of this study was to investigate the association between first-trimester exposure to specific $\mathrm{PM}_{2.5}$ chemical components and ozone, and placentamediated pregnancy complications in Tokyo, one of the world's major cities.

\section{Methods}

\section{Study area and participants}

Our study area included 23 Tokyo wards located on the east side of Tokyo, with a total land area of roughly 627 square kilometres. The population of the 23 wards was about $9,272,000$ as of 1 October 2015 [15]. Tokyo has a humid subtropical climate, and the annual average temperature is around $16{ }^{\circ} \mathrm{C}$. The average annual urban background concentrations of $\mathrm{PM}_{2.5}$ in the study area (e.g., $16.9 \mu \mathrm{g} / \mathrm{m}^{3}$ in 2014 ) is higher than the nationwide background concentrations of $\mathrm{PM}_{2.5}$ (e.g., $14.7 \mu \mathrm{g} / \mathrm{m}^{3}$ in 2014) [16].

We collected data on all the live births and stillbirths after 22 weeks of gestation at 39 cooperating hospitals within the study area, from January 2013 to December 2015 (a total of 89,417 births), which were extracted from the Japan Perinatal Registry Network database, a hospital-based registry (mainly university hospitals and local general hospitals) managed by the Japan Society of Obstetrics and Gynaecology. Details of the database are described elsewhere [17]. The database included roughly two-fifths of the total births in the study area for the study period. The data are routinely input by attending physicians via a standardised electronic form, and checked with respect to uniform coding specifications and diagnostic criteria for complications by the Perinatal Committee of the Society [18]. We used anonymised information on maternal age, height, weight, parity, gestational age, smoking habits and alcohol drinking, infertility treatment, medical history, diagnoses of obstetric complications, such as preeclampsia and placental abruption, mode of delivery, neonatal records, and the hospital at which the woman delivered.

From the 89,417 births including multiple births, we firstly restricted to 85,496 singleton births (85,496 women). Then, we excluded 254 women without information on (at least one of) age at delivery, infant sex, and parity, and 132 women who delivered infants born after 42 weeks of gestation. In Japan, some women return to their hometown near term and deliver at a hospital near their parents' home (known as 'satogaeri' in Japanese). Therefore, as such women may not have resided in our target area during early pregnancy, we also excluded them $(n=1656)$ to avoid exposure misclassification during the first trimester. In the end, 83,454 women (22-41 weeks of gestation) were included in the analysis. The study protocol was approved by the Ethics Committee of Faculty of Medicine, Toho University [A18049_A20024].

\section{Measurement of fine particulate matter and its chemical components}

We obtained air pollutant data, including the daily mean concentrations of total $\mathrm{PM}_{2.5}$ and the maximum 8-h mean concentrations of ozone, measured at an urban background monitoring station (Harumi monitoring station, $35.4^{\circ} \mathrm{N}, 139.5^{\circ} \mathrm{E}$ ) (Fig. S1) near the monitoring point of $\mathrm{PM}_{2.5}$ chemical components, from the Japan National Institute for Environmental Studies' atmospheric environment database. The $\beta$-ray absorption method was used for $\mathrm{PM}_{2.5}$ measurement, and the ultraviolet absorption method was used for ozone measurement. Since there are several urban background monitoring stations in the study area, we confirmed that the $\mathrm{PM}_{2.5}$ and ozone concentrations at the Harumi station were strongly correlated with those at the other stations (Pearson's correlation coefficients $>0.9$ ), and thus considered that the background concentrations of $\mathrm{PM}_{2.5}$ and ozone were spatially homogeneous within our target area. Finally, we obtained the daily mean ambient temperatures from the Japan Meteorological Agency. 
From April 2013 to the end of the study period in December 2015, daily sampling of $\mathrm{PM}_{2.5}$ (from 10:00 a.m. to 9:00 a.m. of the next day) was performed at the Tokyo Metropolitan Research Institute for Environmental Protection, located in the southeast of the study area $\left(35.7^{\circ} \mathrm{N}\right.$, $139.8^{\circ} \mathrm{E}$, roughly $5 \mathrm{~km}$ east of the Harumi monitoring station) (Fig. S1). This institute is considered able to measure the typical ambient air pollutant concentrations in the study area [19]. Using an FRM-2000 sampler (Rupprecht and Patashnick, Albany, NY, USA), samples were collected on a quartz-fibre filter (47 mm diameter, 2500 QAT-UP; Pall Life Sciences, Port Washington, NY, USA), following the Federal Reference Methods of the US Environmental Protection Agency [9]. Based on the standardised protocol of the Ministry of the Environment, Japan [20], total carbon, including organic carbon (OC) and elemental carbon (EC), was analysed using a dual optical carbon analyser (OCEC Carbon Aerosol Analyzer; Sunset Laboratory Inc., Tigard, OR, USA); and the ions, including nitrate, sulphate, ammonium, chloride, sodium, potassium and calcium, were analysed using an ion chromatograph (Dionex ICS-5000; Thermo Fisher Scientific Inc., Waltham, MA, USA). Details of the air sampling and chemical analysis are described elsewhere [21].

As we did not have information on participants' residential address, we assigned measurements at the Harumi monitoring station (total $\mathrm{PM}_{2.5}$ and ozone) and Tokyo Metropolitan Research Institute ( $\mathrm{PM}_{2.5}$ components) to all the women. Based on the birth date and gestational age determined by ultrasound findings during early pregnancy, we estimated the period of the first trimester ( $0-13$ weeks of gestation), and calculated the first trimester average of the respective pollutant concentrations as the main exposure. As the control exposure windows, we used the average concentrations over the 3 months before pregnancy and the second trimester average concentrations (14-27 weeks of gestation).

\section{Placenta-mediated pregnancy complications}

We defined placenta-mediated pregnancy complications as a composite outcome, including SGA, preeclampsia, placental abruption and/or stillbirth (antepartum death) [12]. SGA was defined as birth weight below the 10th percentile according to gestational age, infant sex and parity $(0$ or $\geq 1)$, based on the Japanese neonatal anthropometric chart [22]. Preeclampsia and placental abruption were based on the diagnosis by attending physicians. At the study period, preeclampsia was diagnosed in women presenting with a new onset of hypertension (systolic blood pressure $\geq 140$ $\mathrm{mmHg}$ and/or diastolic blood pressure $\geq 90 \mathrm{mmHg}$ ) after 20 weeks of gestation and proteinuria (two or more dipstick readings of $3+$ or greater, or a $24-\mathrm{h}$ urine collection containing at least $300 \mathrm{mg}$ of protein) [23].

\section{Statistical methods}

All statistical analyses were performed with Stata15 for Windows (Stata Corporation, College Station, TX, USA).

The women were categorised into five groups according to their level of exposure to total $\mathrm{PM}_{2.5}$, its chemical components and ozone during the first trimester. The data in this study had a hierarchical structure that the participants were nested within hospitals. To explore the association between exposure to pollutants during the first trimester, and placenta-mediated pregnancy complications, as a composite outcome and in terms of individual complications, we considered this hierarchical structure, and applied a multilevel logistic regression model with the hospital as a random effect. With the lowest concentration group as the reference, first the odds ratios (ORs) and 95\% confidence intervals (CIs) of placenta-mediated pregnancy complications were estimated, after adjustment for maternal age at delivery ( $<25,25-29,30-34, \geq 35$ years), birth year (2013, 2014, 2015) and season of conception (spring, summer, autumn, winter). Then, the smoking habits and alcohol drinking (yes, no, missing), prepregnancy body mass index $\left(<18.5,18.5-24.9, \geq 25 \mathrm{~kg} / \mathrm{m}^{2}\right.$, missing), current history of diabetes/gestational diabetes (yes, no), infertility treatment (no, ovarian stimulation/artificial insemination by sperm from husband, assisted reproductive technology) and parity $(0,1, \geq 2)$ were included in the model as potential confounding factors. For the association between $\mathrm{PM}_{2.5}$ and a composite outcome, we checked whether natural cubic spline model (non-linear model) was superior to a linear model, and observed no significant divergence from linearity. Then, the ORs per interquartile range increase (IQR) in the pollutant concentrations were also estimated. We treated pollutant exposure over the 3 months before pregnancy and over the second trimester as the control exposure windows, and conducted the same analysis.

We investigated the respective associations between firsttrimester exposure to specific $\mathrm{PM}_{2.5}$ chemical components one-by-one and placenta-mediated pregnancy complications (single-component model). Then, we constructed a multicomponent model, which included all components associated with the composite outcome in the single-component models, to assess which components had an independent effect on the outcome. We further checked whether the first trimester was a sensitive period for the outcome occurrence (adjusted for exposure over the 3 months before pregnancy and the second trimester), and whether the observed association was affected by the confounding of total $\mathrm{PM}_{2.5}$ and ozone, or temperature (adjusted for average concentrations of $\mathrm{PM}_{2.5}$ and ozone, and average temperature during the first trimester). Also, since past history of preeclampsia, placental abruption, stillbirth and/or foetal growth restriction were risk factors for placenta-mediated pregnancy complications [13], 
Table 1 Characteristics of 83,454 women according to quintiles of total $\mathrm{PM}_{2.5}$ concentrations over the first trimester (0-13 weeks of gestation) in 23 Tokyo wards, from 2013 to 2015.

\begin{tabular}{|c|c|c|c|c|c|c|c|c|c|c|}
\hline \multirow[b]{3}{*}{ Variables } & \multicolumn{10}{|l|}{ Quintile } \\
\hline & \multicolumn{2}{|c|}{1 (lowest) } & \multicolumn{2}{|l|}{2} & \multicolumn{2}{|l|}{3} & \multicolumn{2}{|l|}{4} & \multicolumn{2}{|c|}{5 (highest) } \\
\hline & $n$ & $\%$ & $n$ & $\%$ & $n$ & $\%$ & $n$ & $\%$ & $n$ & $\%$ \\
\hline $\begin{array}{l}\text { Total } \mathrm{PM}_{2.5} \text {, median } \\
\text { (interquartile range) }\left(\mu \mathrm{g} / \mathrm{m}^{3}\right)\end{array}$ & \multicolumn{2}{|c|}{$14.0(13.1-14.3)$} & \multicolumn{2}{|c|}{$15.2(14.9-15.5)$} & \multicolumn{2}{|c|}{$16.1(15.8-16.4)$} & \multicolumn{2}{|c|}{$17.8(17.5-18.5)$} & \multicolumn{2}{|c|}{$21.3(20.5-21.7)$} \\
\hline No. of women & \multicolumn{2}{|l|}{16,616} & \multicolumn{2}{|l|}{16,736} & \multicolumn{2}{|l|}{16,678} & \multicolumn{2}{|l|}{16,714} & \multicolumn{2}{|l|}{16,710} \\
\hline \multicolumn{11}{|c|}{ Maternal age at delivery (years) } \\
\hline$<25$ & 680 & 4.1 & 661 & 4.0 & 661 & 4.0 & 594 & 3.6 & 638 & 3.8 \\
\hline $25-29$ & 2707 & 16.3 & 2691 & 16.1 & 2762 & 16.6 & 2723 & 16.3 & 2631 & 15.8 \\
\hline $30-34$ & 5723 & 34.4 & 5697 & 34.0 & 5782 & 34.7 & 5699 & 34.1 & 5681 & 34.0 \\
\hline$\geq 35$ & 7506 & 45.2 & 7687 & 45.9 & 7473 & 44.8 & 7698 & 46.1 & 7760 & 46.4 \\
\hline \multicolumn{11}{|l|}{ Parity } \\
\hline 0 & 9918 & 59.7 & 10,178 & 60.8 & 10,060 & 60.3 & 10,020 & 60.0 & 10,185 & 61.0 \\
\hline 1 & 5285 & 31.8 & 5158 & 30.8 & 5190 & 31.1 & 5222 & 31.2 & 5064 & 30.3 \\
\hline$\geq 2$ & 1413 & 8.5 & 1400 & 8.4 & 1428 & 8.6 & 1472 & 8.8 & 1461 & 8.7 \\
\hline \multicolumn{11}{|l|}{ Smoking habits } \\
\hline No & 12,757 & 95.1 & 13,192 & 96.9 & 13,109 & 97.1 & 13,443 & 97.2 & 13,312 & 95.7 \\
\hline Yes & 651 & 4.9 & 416 & 3.1 & 390 & 2.9 & 393 & 2.8 & 592 & 4.3 \\
\hline \multicolumn{11}{|l|}{ Alcohol drinking } \\
\hline No & 11,676 & 94.4 & 11,693 & 96.5 & 11,642 & 96.5 & 11,815 & 97.1 & 11,311 & 95.6 \\
\hline Yes & 688 & 5.6 & 425 & 3.5 & 429 & 3.6 & 355 & 2.9 & 525 & 4.4 \\
\hline \multicolumn{11}{|c|}{ Prepregnancy body mass index $\left(\mathrm{kg} / \mathrm{m}^{2}\right)$} \\
\hline$<18.5$ & 2768 & 19.5 & 2774 & 19.5 & 2792 & 19.7 & 2678 & 18.9 & 2794 & 19.9 \\
\hline $18.5-24.9$ & 10,352 & 72.9 & 10,412 & 73.3 & 10,341 & 73.1 & 10,412 & 73.7 & 10,235 & 72.7 \\
\hline$\geq 25.0$ & 1082 & 7.6 & 1015 & 7.2 & 1015 & 7.2 & 1046 & 7.4 & 1049 & 7.5 \\
\hline \multicolumn{11}{|c|}{ Current history of diabetes/gestational diabetes } \\
\hline No & 15,750 & 94.8 & 15,924 & 95.2 & 15,809 & 94.8 & 15,792 & 94.5 & 15,850 & 94.9 \\
\hline Yes & 866 & 5.2 & 812 & 4.9 & 869 & 5.2 & 922 & 5.5 & 860 & 5.2 \\
\hline Infertility treatment & & & & & & & & & & \\
\hline No & 13,881 & 83.5 & 14,131 & 84.4 & 14,179 & 85.0 & 13,965 & 83.6 & 13,998 & 83.8 \\
\hline $\begin{array}{l}\text { Ovarian stimulation/ } \\
\text { artificial insemination by } \\
\text { sperm from husband }\end{array}$ & 1047 & 6.3 & 1028 & 6.1 & 952 & 5.7 & 1149 & 6.9 & 1165 & 7.0 \\
\hline $\begin{array}{l}\text { Assisted reproductive } \\
\text { technology }\end{array}$ & 1688 & 10.2 & 1577 & 9.4 & 1547 & 9.3 & 1600 & 9.6 & 1547 & 9.3 \\
\hline Past history of complications & & & & & & & & & & \\
\hline Foetal growth restriction & 54 & 0.3 & 62 & 0.4 & 79 & 0.5 & 80 & 0.5 & 72 & 0.4 \\
\hline Preeclampsia & 29 & 0.2 & 19 & 0.1 & 22 & 0.1 & 33 & 0.2 & 28 & 0.2 \\
\hline Placental abruption & 38 & 0.2 & 36 & 0.2 & 37 & 0.2 & 41 & 0.3 & 42 & 0.3 \\
\hline Stillbirth & 83 & 0.5 & 96 & 0.6 & 86 & 0.5 & 101 & 0.6 & 83 & 0.5 \\
\hline $\begin{array}{l}\text { Placenta-mediated } \\
\text { pregnancy complications as } \\
\text { a composite outcome }\end{array}$ & 1669 & 10.0 & 1792 & 10.7 & 1761 & 10.6 & 1783 & 10.7 & 1658 & 9.9 \\
\hline Small for gestational age & 1253 & 7.6 & 1368 & 8.2 & 1343 & 8.1 & 1371 & 8.2 & 1271 & 7.6 \\
\hline Preeclampsia & 213 & 1.3 & 222 & 1.3 & 215 & 1.3 & 234 & 1.4 & 220 & 1.3 \\
\hline Placental abruption & 263 & 1.6 & 286 & 1.7 & 272 & 1.6 & 253 & 1.5 & 234 & 1.4 \\
\hline Stillbirth & 77 & 0.5 & 53 & 0.3 & 65 & 0.4 & 67 & 0.4 & 61 & 0.4 \\
\hline
\end{tabular}




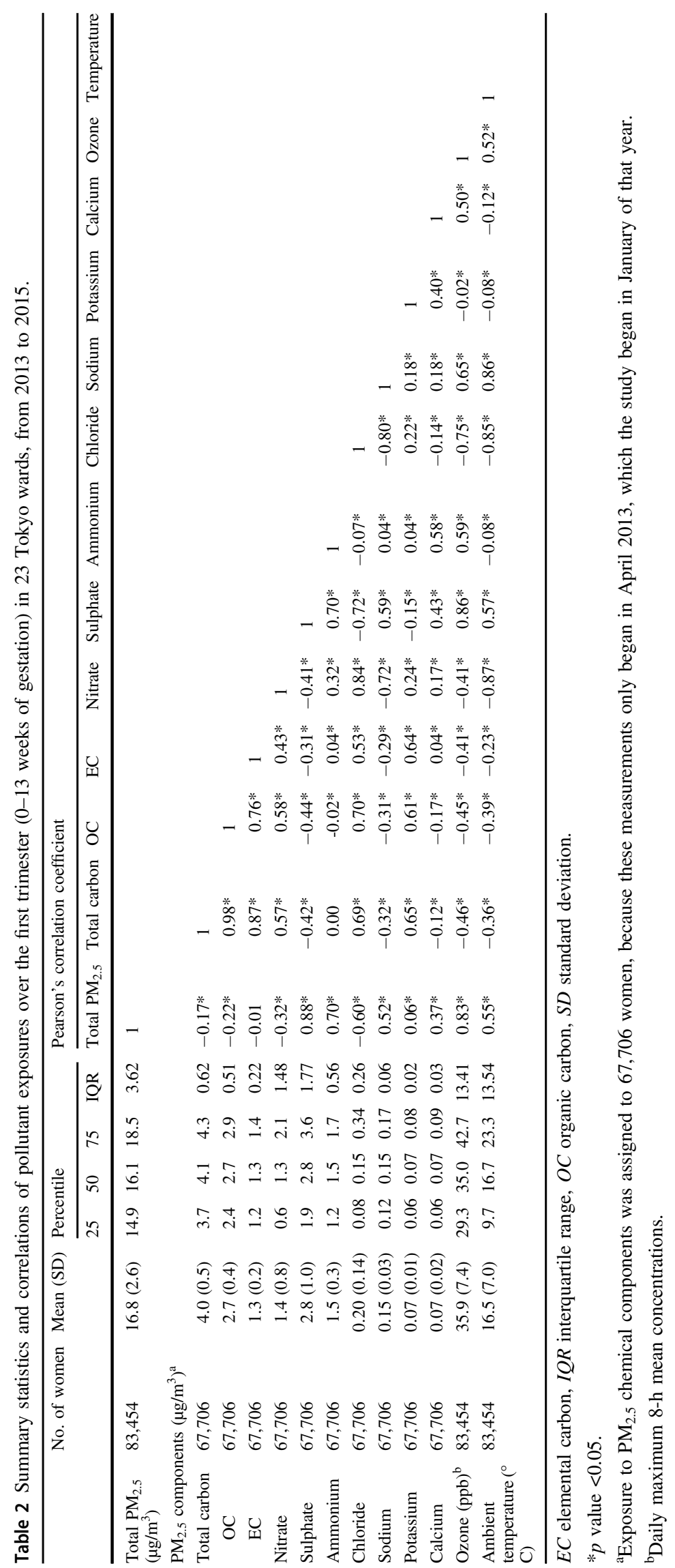


Table 3 Odds ratios (ORs) and 95\% confidence intervals (CIs) for the association between exposure to $\mathrm{PM}_{2.5}$ and ozone over the first trimester (0-13 weeks of gestation) and placenta-mediated pregnancy complications.

\begin{tabular}{|c|c|c|c|c|c|c|}
\hline & \multicolumn{5}{|l|}{ Quintile } & \multirow[b]{2}{*}{ Per IQR increase } \\
\hline & 1 (lowest) & 2 & 3 & 4 & 5 (highest) & \\
\hline \multicolumn{7}{|l|}{ Total $\mathrm{PM}_{2.5}\left(\mu \mathrm{g} / \mathrm{m}^{3}\right)$} \\
\hline Median (IQR) & $14.0(13.1-14.3)$ & $15.2(14.9-15.5)$ & $16.1(15.8-16.4)$ & $17.8(17.5-18.5)$ & $21.3(20.5-21.7)$ & \\
\hline No. of women & 16,616 & 16,736 & 16,678 & 16,714 & 16,710 & 83,454 \\
\hline No. of outcome & 1669 & 1792 & 1761 & 1783 & 1658 & 8663 \\
\hline OR $(95 \% \mathrm{CI})^{\mathrm{a}}$ & Reference & $1.09(1.01-1.18)$ & $1.11(1.02-1.22)$ & $1.12(1.01-1.25)$ & $1.07(0.96-1.20)$ & $1.00(0.94-1.05)$ \\
\hline OR $(95 \% \mathrm{CI})^{\mathrm{b}}$ & Reference & $1.09(1.01-1.18)$ & $1.11(1.02-1.22)$ & $1.13(1.02-1.25)$ & $1.07(0.96-1.19)$ & $0.99(0.94-1.05)$ \\
\hline \multicolumn{7}{|c|}{$\mathrm{PM}_{2.5}$ components $\left(\mu \mathrm{g} / \mathrm{m}^{3}\right)$} \\
\hline \multicolumn{7}{|l|}{ Total carbon } \\
\hline Median (IQR) & $3.2(2.8-3.5)$ & $3.7(3.7-3.8)$ & $4.1(4.0-4.1)$ & $4.2(4.2-4.3)$ & $4.6(4.4-4.9)$ & \\
\hline No. of women & 13,508 & 13,492 & 13,584 & 13,569 & 13,553 & 67,706 \\
\hline No. of outcome & 1403 & 1358 & 1433 & 1385 & 1479 & 7058 \\
\hline OR $(95 \% \mathrm{CI})^{\mathrm{a}}$ & Reference & $0.96(0.87-1.06)$ & $1.10(0.98-1.22)$ & $1.06(0.95-1.18)$ & $1.11(0.98-1.25)$ & $1.10(1.04-1.17)$ \\
\hline OR $(95 \% \mathrm{CI})^{\mathrm{b}}$ & Reference & $0.96(0.87-1.06)$ & $1.10(0.98-1.23)$ & $1.06(0.95-1.19)$ & $1.11(0.98-1.26)$ & $1.10(1.04-1.17)$ \\
\hline \multicolumn{7}{|l|}{$\mathrm{OC}$} \\
\hline Median (IQR) & $2.1(1.8-2.3)$ & $2.4(2.4-2.5)$ & $2.7(2.7-2.8)$ & $2.9(2.8-2.9)$ & $3.2(3.0-3.3)$ & \\
\hline No. of women & 13,540 & 13,486 & 13,569 & 13,526 & 13,585 & 67,706 \\
\hline No. of outcome & 1398 & 1351 & 1379 & 1402 & 1528 & 7058 \\
\hline OR $(95 \% \mathrm{CI})^{\mathrm{a}}$ & Reference & $0.97(0.87-1.07)$ & $1.07(0.97-1.19)$ & $1.10(0.98-1.22)$ & $1.19(1.05-1.34)$ & $1.14(1.08-1.22)$ \\
\hline OR $(95 \% \mathrm{CI})^{\mathrm{b}}$ & Reference & $0.97(0.87-1.07)$ & $1.08(0.97-1.20)$ & $1.10(0.99-1.23)$ & $1.20(1.06-1.36)$ & $1.15(1.08-1.22)$ \\
\hline \multicolumn{7}{|l|}{$\mathrm{EC}$} \\
\hline Median (IQR) & $1.1(1.0-1.2)$ & $1.2(1.2-1.3)$ & $1.3(1.3-1.3)$ & $1.4(1.4-1.4)$ & $1.5(1.5-1.5)$ & \\
\hline No. of women & 13,483 & 13,549 & 13,543 & 13,547 & 13,584 & 67,706 \\
\hline No. of outcome & 1440 & 1452 & 1373 & 1365 & 1428 & 7058 \\
\hline OR $(95 \% \mathrm{CI})^{\mathrm{a}}$ & Reference & $1.00(0.91-1.11)$ & $0.91(0.83-1.01)$ & $0.94(0.86-1.04)$ & $0.99(0.89-1.10)$ & $1.01(0.96-1.07)$ \\
\hline OR $(95 \% \mathrm{CI})^{\mathrm{b}}$ & Reference & $1.00(0.91-1.10)$ & $0.91(0.82-1.00)$ & $0.94(0.85-1.03)$ & $0.98(0.89-1.09)$ & $1.01(0.96-1.07)$ \\
\hline \multicolumn{7}{|l|}{ Nitrate } \\
\hline Median (IQR) & $0.3(0.2-0.4)$ & $0.7(0.6-0.8)$ & $1.3(1.1-1.5)$ & $1.9(1.8-2.1)$ & $2.6(2.5-2.7)$ & \\
\hline No. of women & 13,502 & 13,547 & 13,537 & 13,539 & 13,581 & 67,706 \\
\hline No. of outcome & 1416 & 1424 & 1424 & 1414 & 1380 & 7058 \\
\hline OR $(95 \% \mathrm{CI})^{\mathrm{a}}$ & Reference & $0.96(0.88-1.05)$ & $1.01(0.91-1.12)$ & $1.02(0.91-1.15)$ & $1.02(0.90-1.17)$ & $1.03(0.95-1.13)$ \\
\hline OR $(95 \% \mathrm{CI})^{\mathrm{b}}$ & Reference & $0.96(0.88-1.05)$ & $1.02(0.92-1.13)$ & $1.03(0.91-1.16)$ & $1.03(0.90-1.17)$ & $1.03(0.95-1.13)$ \\
\hline \multicolumn{7}{|l|}{ Sulphate } \\
\hline Median (IQR) & $1.7(1.5-1.7)$ & $2.0(1.9-2.1)$ & $2.8(2.5-2.9)$ & $3.4(3.2-3.6)$ & $4.1(3.9-4.8)$ & \\
\hline No. of women & 13,528 & 13,481 & 13,547 & 13,584 & 13,566 & 67,706 \\
\hline No. of outcome & 1442 & 1405 & 1380 & 1443 & 1388 & 7058 \\
\hline OR $(95 \% \mathrm{CI})^{\mathrm{a}}$ & Reference & $1.00(0.91-1.11)$ & $1.01(0.89-1.14)$ & $1.10(0.96-1.25)$ & $1.10(0.95-1.28)$ & $1.05(0.97-1.13)$ \\
\hline OR $(95 \% \mathrm{CI})^{\mathrm{b}}$ & Reference & $1.00(0.91-1.11)$ & $1.01(0.89-1.15)$ & $1.10(0.96-1.26)$ & $1.10(0.95-1.28)$ & $1.05(0.97-1.13)$ \\
\hline \multicolumn{7}{|l|}{ Ammonium } \\
\hline Median (IQR) & $1.0(1.0-1.1)$ & $1.2(1.2-1.3)$ & $1.5(1.4-1.6)$ & $1.7(1.7-1.7)$ & $1.8(1.8-1.9)$ & \\
\hline No. of women & 13,452 & 13,536 & 13,558 & 13,611 & 13,549 & 67,706 \\
\hline No. of outcome & 1447 & 1436 & 1417 & 1393 & 1365 & 7058 \\
\hline OR $(95 \% \mathrm{CI})^{\mathrm{a}}$ & Reference & $0.98(0.90-1.06)$ & $1.02(0.93-1.11)$ & $1.03(0.93-1.15)$ & $1.03(0.92-1.16)$ & $1.03(0.95-1.12)$ \\
\hline OR $(95 \% \mathrm{CI})^{\mathrm{b}}$ & Reference & $0.98(0.90-1.06)$ & $1.01(0.93-1.11)$ & $1.03(0.93-1.15)$ & $1.03(0.92-1.16)$ & $1.03(0.95-1.12)$ \\
\hline
\end{tabular}


Table 3 (continued)

\begin{tabular}{|c|c|c|c|c|c|c|}
\hline & \multicolumn{5}{|l|}{ Quintile } & \multirow[b]{2}{*}{ Per IQR increase } \\
\hline & 1 (lowest) & 2 & 3 & 4 & 5 (highest) & \\
\hline \multicolumn{7}{|l|}{ Chloride } \\
\hline Median (IQR) & $0.04(0.03-0.06)$ & $0.09(0.08-0.11)$ & $0.15(0.14-0.18)$ & $0.30(0.26-0.34)$ & $0.41(0.39-0.44)$ & \\
\hline No. of women & 13,531 & 13,497 & 13,571 & 13,508 & 13,599 & 67,706 \\
\hline No. of outcome & 1379 & 1404 & 1412 & 1441 & 1422 & 7058 \\
\hline OR $(95 \% \mathrm{CI})^{\mathrm{a}}$ & Reference & $1.00(0.92-1.09)$ & $1.06(0.96-1.17)$ & $1.16(1.01-1.33)$ & $1.11(0.96-1.29)$ & $1.04(0.95-1.14)$ \\
\hline OR $(95 \% \mathrm{CI})^{\mathrm{b}}$ & Reference & $1.00(0.92-1.09)$ & $1.06(0.97-1.17)$ & $1.16(1.01-1.33)$ & $1.11(0.96-1.28)$ & $1.04(0.95-1.14)$ \\
\hline \multicolumn{7}{|l|}{ Sodium } \\
\hline Median (IQR) & $0.10(0.09-0.10)$ & $0.13(0.12-0.13)$ & $0.15(0.15-0.16)$ & $0.17(0.16-0.17)$ & $0.19(0.18-0.19)$ & \\
\hline No. of women & 13,516 & 13,546 & 13,561 & 13,499 & 13,584 & 67,706 \\
\hline No. of outcome & 1388 & 1391 & 1415 & 1365 & 1499 & 7058 \\
\hline OR $(95 \% \mathrm{CI})^{\mathrm{a}}$ & Reference & $1.02(0.94-1.10)$ & $1.08(0.98-1.18)$ & $1.02(0.92-1.14)$ & $1.15(1.02-1.29)$ & $1.10(1.03-1.18)$ \\
\hline OR $(95 \% \mathrm{CI})^{\mathrm{b}}$ & Reference & $1.02(0.94-1.11)$ & $1.08(0.98-1.19)$ & $1.03(0.93-1.15)$ & $1.16(1.03-1.31)$ & $1.11(1.03-1.18)$ \\
\hline \multicolumn{7}{|l|}{ Potassium } \\
\hline Median (IQR) & $0.06(0.05-0.06)$ & $0.06(0.06-0.06)$ & $0.07(0.06-0.07)$ & $0.08(0.07-0.08)$ & $0.09(0.09-0.10)$ & \\
\hline No. of women & 13,483 & 13,590 & 13,510 & 13,473 & 13,650 & 67,706 \\
\hline No. of outcome & 1409 & 1354 & 1404 & 1425 & 1466 & 7058 \\
\hline OR $(95 \% \mathrm{CI})^{\mathrm{a}}$ & Reference & $0.95(0.88-1.04)$ & $0.99(0.91-1.08)$ & $1.04(0.95-1.14)$ & $1.03(0.94-1.12)$ & $1.05(1.00-1.09)$ \\
\hline OR $(95 \% \mathrm{CI})^{\mathrm{b}}$ & Reference & $0.95(0.88-1.03)$ & $0.98(0.90-1.07)$ & $1.04(0.95-1.13)$ & $1.03(0.94-1.12)$ & $1.05(1.00-1.09)$ \\
\hline \multicolumn{7}{|l|}{ Calcium } \\
\hline Median (IQR) & $0.05(0.04-0.05)$ & $0.06(0.06-0.07)$ & $0.07(0.07-0.07)$ & $0.09(0.08-0.09)$ & $0.11(0.10-0.11)$ & \\
\hline No. of women & 13,507 & 13,574 & 13,496 & 13,539 & 13,590 & 67,706 \\
\hline No. of outcome & 1411 & 1389 & 1490 & 1407 & 1361 & 7058 \\
\hline OR $(95 \% \mathrm{CI})^{\mathrm{a}}$ & Reference & $0.96(0.88-1.04)$ & $1.04(0.95-1.13)$ & $1.02(0.93-1.12)$ & $1.02(0.92-1.13)$ & $1.02(0.97-1.07)$ \\
\hline OR $(95 \% \mathrm{CI})^{\mathrm{b}}$ & Reference & $0.95(0.87-1.04)$ & $1.04(0.96-1.13)$ & $1.02(0.93-1.12)$ & $1.02(0.92-1.13)$ & $1.01(0.97-1.07)$ \\
\hline \multicolumn{7}{|l|}{ Ozone (ppb) } \\
\hline Median (IQR) & $25.8(25.0-26.5)$ & $30.3(28.8-31.4)$ & 33.8 (32.9-36.0) & $40.4(38.5-42.1)$ & $45.4(44.1-47.8)$ & \\
\hline No. of women & 16,669 & 16,700 & 16,670 & 16,707 & 16,708 & 83,454 \\
\hline No. of outcome & 1731 & 1732 & 1746 & 1716 & 1738 & 8663 \\
\hline OR $(95 \% \mathrm{CI})^{\mathrm{a}}$ & Reference & $1.02(0.93-1.13)$ & $1.04(0.92-1.17)$ & $1.08(0.96-1.23)$ & $1.12(0.98-1.28)$ & $1.05(0.97-1.14)$ \\
\hline OR $(95 \% \mathrm{CI})^{\mathrm{b}}$ & Reference & $1.02(0.93-1.13)$ & $1.04(0.92-1.18)$ & $1.09(0.96-1.23)$ & $1.12(0.98-1.28)$ & $1.05(0.97-1.14)$ \\
\hline
\end{tabular}

$E C$ elemental carbon, $I Q R$ interquartile range, $O C$ organic carbon.

${ }^{\mathrm{a}}$ Adjusted for maternal age, birth year, season of conception.

${ }^{\mathrm{b}}$ Additionally adjusted for smoking, alcohol drinking, prepregnancy body mass index, current history of diabetes/gestational diabetes, infertility treatment and parity.

sensitivity analyses were performed after excluding women with such past histories, and after restricting to nulliparae. Finally, we used the average concentrations over the 8th-12th gestational weeks (i.e., the early stage of placentation) as a specific exposure window for the pathogenesis of placenta-mediated pregnancy complications [24].

\section{Results}

Mean age at delivery of the 83,454 women was 33.7 years (standard deviation $(\mathrm{SD})=5.0$ ), with the percentage $\geq 35$ years accounting for $45.7 \%$. The distribution of characteristics did not differ substantially among the five groups based on total $\mathrm{PM}_{2.5}$ concentrations over the first trimester (Table 1). In the overall population, placenta-mediated pregnancy complications were identified in 8663 women (10.4\%), with the numbers for individual complications being 6606 for SGA, 1104 for preeclampsia, 1308 for placental abruption, and 323 for stillbirth.

Summary statistics of pollutants exposure over the first trimester are shown in Table 2. The average exposure to total $\mathrm{PM}_{2.5}$ was $16.8(\mathrm{SD}=2.6) \mu \mathrm{g} / \mathrm{m}^{3}$. Exposure to $\mathrm{PM}_{2.5}$ chemical components was assigned to 67,706 women, 
because these measurements only began in April 2013, which the study began in January of that year. The major components were total carbon (OC and EC), nitrate, sulphate and ammonium, and their average exposures were 4.0 (0.5), $1.4(0.8), 2.8(1.0)$, and $1.5(0.3) \mu \mathrm{g} / \mathrm{m}^{3}$, respectively. The correlation coefficient between OC and EC was 0.76 .

The association between pollutants exposure over the first trimester and placenta-mediated pregnancy complications is shown in Table 3. Total $\mathrm{PM}_{2.5}$ and ozone were not significantly associated with a composite outcome. Compared with the lowest group, however, the point estimates of the OR in the highest group were above unity (OR for $\mathrm{PM}_{2.5}=1.07,95 \% \mathrm{CI}=0.95-1.19$; for ozone 1.12, 0.98-1.28). With regard to $\mathrm{PM}_{2.5}$ chemical components, total carbon, particularly $\mathrm{OC}$ and sodium were positively associated with outcome. The ORs per IQR increase in the concentrations of carbon (IQR $=0.62 \mu \mathrm{g} / \mathrm{m}^{3}$ ), OC $\left(0.51 \mu \mathrm{g} / \mathrm{m}^{3}\right)$ and sodium $\left(0.06 \mu \mathrm{g} / \mathrm{m}^{3}\right)$ were $1.10(95 \%$ $\mathrm{CI}=1.04-1.17), 1.15$ (1.08-1.22) and 1.11 (1.03-1.18), respectively. Pollutant exposure over the 3 months before pregnancy was not associated with outcome (Table S1). With respect to exposure over the second trimester, there was no evidence of increased odds of outcome, in fact, decreased odds were observed with increasing concentrations of some components (Table S2).

We investigated in detail the association of carbon and sodium with placenta-mediated pregnancy complications (Fig. 1). Overall, the tendency towards a positive association persisted. For example, the multi-component model suggested that carbon and sodium were independently associated with outcome. Also, exposure to these components from 8 to 12 weeks was positively associated with outcome.

The respective associations for individual outcomes of placenta-mediated pregnancy complications are summarised in Tables S3. In particularly, we observed that OC was consistently associated with all four complications; the ORs per IQR increase were $1.10(95 \% \mathrm{CI}=1.02-1.17)$ for SGA, $1.16(0.99-1.37)$ for preeclampsia, 1.29 (1.11-1.51) for placental abruption and 2.04 (1.49-2.77) for stillbirth.

\section{Discussion}

In the analysis of singleton pregnant women in Tokyo between 2013 and 2015, exposure to total $\mathrm{PM}_{2.5}$ was not associated with placenta-mediated pregnancy complications (mixed outcome of SGA, preeclampsia, placental abruption and stillbirth). In the latest report by the US Environmental Protection Agency, the evidence for the association between maternal exposure to total $\mathrm{PM}_{2.5}$ and pregnancy and birth outcomes, including SGA, preeclampsia and stillbirth, was not consistent [9]. In contrast, we here observed that an increase in the concentrations of some $\mathrm{PM}_{2.5}$ chemical components, such as total carbon and sodium, was clearly associated with an elevated occurrence of pregnancy complications. This positive association was observed for exposure over the first trimester, but not for exposure over the 3 months before pregnancy or over the second trimester.

After adjustment for total $\mathrm{PM}_{2.5}$, we found that exposure to total carbon was positively associated with placentamediated pregnancy complications. This result suggested that carbon-containing components of $\mathrm{PM}_{2.5}$ may have contributed to pregnancy complications. Carbon is a major component in $\mathrm{PM}_{2.5}$ mass concentrations [25]. Some studies in the USA and Canada based on registry data reported that prenatal exposure to total carbon, mainly EC (or black carbon), was associated with the risk of SGA [26, 27]. Further, analysis based on similar data in Florida between 2004 and 2007 suggested that exposure to EC over the first trimester $\left(\right.$ mean $\left.=0.5 \mu \mathrm{g} / \mathrm{m}^{3}\right)$ increased the risk of preeclampsia (OR per IQR $=1.08,95 \% \mathrm{CI}=1.01-1.16)$ and placental abruption $(1.38,1.09-1.75)[3,4]$. This study did not include exposure to OC. Past studies suggested that, among the total carbon components, EC rather than OC seems likely to be associated with adverse perinatal health. In our study, however, OC was consistently associated not only with a composite outcome but also with individual complications. EC is a primary pollutant due to incomplete combustion of fossil fuels and biomass [28], whereas OC has both primary and secondary origins [25]. However, though they differ in source origins, the concentrations of EC and OC are well correlated, and these are complex mixtures, including, for example, polycyclic aromatic hydrocarbons (PAHs). PAHs can cross the placental barrier, and are possible pollutants that affect maternal and child health [29]. Therefore, the association we observed would not be competing with past evidence regarding perinatal health effects of carbon-containing components of $\mathrm{PM}_{2.5}$. We also found a positive association between exposure to sodium and outcome. A few studies found the adverse perinatal health effects from sodium [30]. Although sodium is an indicator component of $\mathrm{PM}_{2.5}$ that originates from sea salt [31], other sea salt-related components, such as chloride, were not associated with the outcome. In this study, we did not observe the adverse effects from nitrate, sulphate or ammonium, which are markers of secondary inorganic aerosols as a major source of $\mathrm{PM}_{2.5}$ [31]. As there is limited evidence regarding the association between $\mathrm{PM}_{2.5}$ components and placenta-mediated pregnancy complications, further studies are required.

Our findings suggested that the first trimester was susceptible to pollutants exposure associated with placentamediated pregnancy complications. The first trimester of pregnancy, especially the latter half, is a crucial period in placentation [11]. Abnormal placentation and failure of 
Fig. 1 Sensitivity analysis of the association between exposure to carbon and sodium over the first trimester (0-13 weeks of gestation) and placenta-mediated pregnancy complications. The odds ratios (ORs) per interquartile range increase in the concentrations of each component were adjusted for maternal age, birth year, season of conception, smoking, alcohol drinking, prepregnancy body mass index, current history of diabetes/gestational diabetes, infertility treatment and parity. The error bars indicate $95 \%$ confidence intervals.

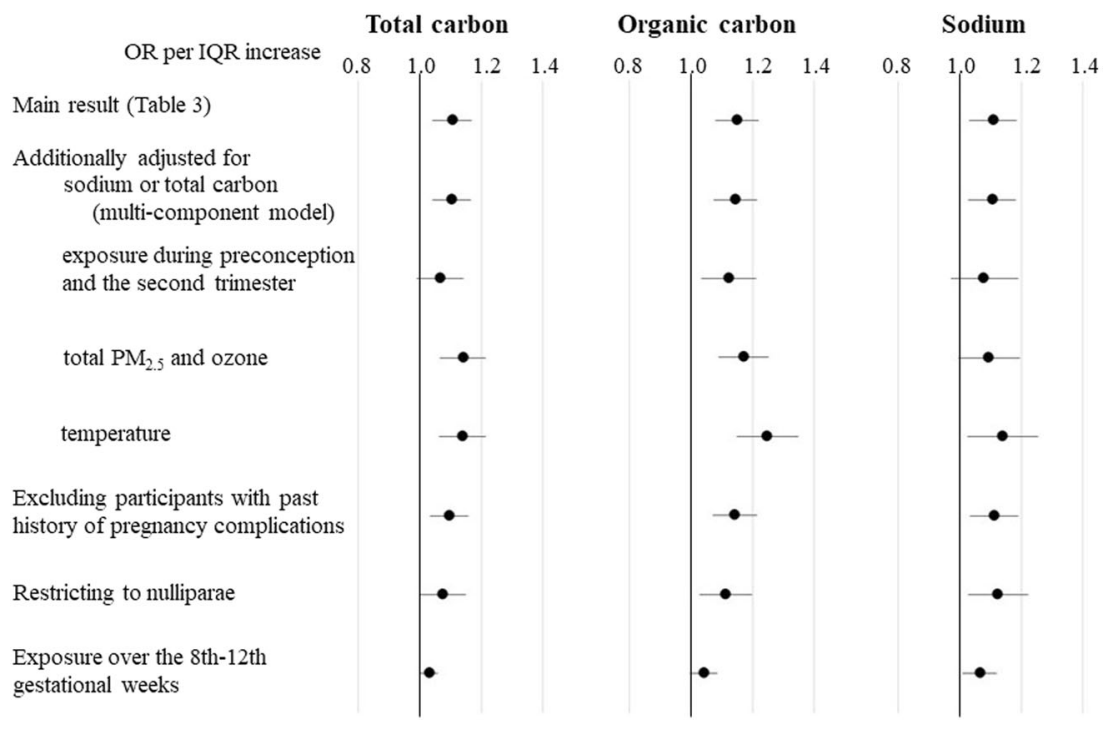

trophoblast invasion into the placental bed are considered to be involved in the pathogenesis of preeclampsia, and to lead to foetal growth restriction related to SGA [11, 32]. Further, it has been noted that impaired placentation is the basis for the development of placental abruption [33]. Inflammation, hypoxia and coagulation in the intrauterine environment appears to contribute to the pathophysiology of abnormal placental development $[12,32]$. These biological reactions are on the biological pathway of exposure to $\mathrm{PM}_{2.5}$ [34], and short-term exposure to $\mathrm{OC}$ was associated with an elevated level of inflammatory biomarkers, such as tumour necrosis factor alpha, in healthy adults [35]. Furthermore, a birth cohort study in Canada reported that hyperhomocysteinemia, which is related to inflammation and increased coagulation [36], was associated with an elevated risk of placenta-mediated pregnancy complications [37]. Plasma levels of homocysteine were higher in taxi drivers, who were routinely exposed to air pollutants, such as PAHs as carbonaceous constituent of $\mathrm{PM}_{2.5}$, than in nonoccupationally exposed individuals [38]. Therefore, it is likely that first-trimester exposure to pollutants, such as OC, has a role in abnormal placentation. Incidentally, the OR point estimates for the association with exposure to some components over the second trimester showed below unity. Since we did not have reason to believe that the direction of this association was biologically plausible, we interpreted this to mean that second trimester exposure had little influence on pregnancy complications.

We previously reported a positive association between exposure to ozone during the first trimester and preeclampsia in 33,380 singleton pregnant women who resided in western Japan between 2005 and 2010 [39]. In the present study, there was no significant association (Table S3). This difference might partially reflect different ozone concentrations, so those in the previous study (mean $=41.3$ $\mathrm{ppb}$ ) tended to be higher than those in the present study (35.3 ppb).

Some methodological issues are worth mentioning. One clear limitation is that we did not consider spatial variability in $\mathrm{PM}_{2.5}$ concentrations within the 23 Tokyo wards; we assessed only temporal variability in these concentrations. In environmental epidemiological study, however, pollutant concentrations measured at the central monitoring station are often assigned to all participants living within a certain distance from the station. In this case, the area of the 23 Tokyo wards can be covered with a buffer size of roughly $20 \mathrm{~km}$ (Fig. S1), and a California study reported that the association between $\mathrm{PM}_{2.5}$ components and birth weight with a $20-\mathrm{km}$ buffer was similar to that with a $10-\mathrm{km}$ buffer [30]. We considered, therefore, that homogeneous pollutant concentrations within the 23 Tokyo wards was an acceptable assumption. However, it is possible that this spatial homogeneous assumption would not apply in the case of some of the components. Also, we assumed that the temporal variation was similar for all components within the 23 studied wards. Thus, we should interpret the respective associations for individual components cautiously. In addition, we did not adjust for heterogeneous spatial pollutants (such as nitrogen dioxide) as co-pollutants [40]. Second, we did not have information on residential mobility during pregnancy. Even after we excluded 'satogaeri' cases, women who resided far away from the study area in early pregnancy might have been included in the study population. However, a review suggested that most moves during pregnancy did not significantly affect exposure estimates, as most were intra-neighbourhood moves, though the percentage of women who moved during pregnancy was not negligible (median $=20 \%$ ) [41]. Third, we did not have information on socioeconomic status as a possible confounding factor [42]. However, by using a multilevel model 
with the hospital as a random effect, we considered a hospital catchment area that likely had a relatively uniform socioeconomic status. Finally, we had a weakness in the generalisability of our results, as the Perinatal Registry database was established mainly with information from university and local general hospitals.

Irrespective of these limitations, to the best of our knowledge, this is the first study focused on the association between exposure to $\mathrm{PM}_{2.5}$ chemical components over the first trimester and placenta-mediated pregnancy complications as a composite outcome. Another strength is that we used continuous filter-based measurements of $\mathrm{PM}_{2.5}$ components in a megacity, Tokyo, and this allowed us to analyse a relatively large sample size. In addition, we analysed data derived from a good-quality clinical database, including information on major confounding factors related to placenta-mediated pregnancy complications, such as smoking habits, prepregnancy overweight, and past history of pregnancy complications.

In conclusion, we found that exposure to some components of $\mathrm{PM}_{2.5}$ over the first trimester was positively associated with placenta-mediated pregnancy complications in Tokyo, a highly urbanised major global city. Our findings suggest that specific components of $\mathrm{PM}_{2.5}$ have harmful effects on placentation in urbanised settings.

Acknowledgements The authors thank Ms. Hitomi Matsushita and Ms. Emi Yamazaki (Department of Environmental and Occupational Health, School of Medicine, Toho University) for research assistance. Data of $\mathrm{PM}_{2.5}$ components were provided from Type II joint research between the National Institute for Environmental Studies and the local environmental research institutes in Japan.

Funding This study was supported by the Japan Society for the Promotion of Science KAKENHI [grant number 18H03388]. The funder had no role in study design, data collection and analysis, decision to publish or preparation of the manuscript.

\section{Compliance with ethical standards}

Conflict of interest The authors declare no competing interests.

Publisher's note Springer Nature remains neutral with regard to jurisdictional claims in published maps and institutional affiliations.

Open Access This article is licensed under a Creative Commons Attribution 4.0 International License, which permits use, sharing, adaptation, distribution and reproduction in any medium or format, as long as you give appropriate credit to the original author(s) and the source, provide a link to the Creative Commons license, and indicate if changes were made. The images or other third party material in this article are included in the article's Creative Commons license, unless indicated otherwise in a credit line to the material. If material is not included in the article's Creative Commons license and your intended use is not permitted by statutory regulation or exceeds the permitted use, you will need to obtain permission directly from the copyright holder. To view a copy of this license, visit http://creativecommons. org/licenses/by/4.0/.

\section{References}

1. Schraufnagel DE, Balmes JR, Cowl CT, De Matteis S, Jung SH, Mortimer K, et al. Air pollution and noncommunicable diseases: a review by the forum of International Respiratory Societies' Environmental Committee, part 1: the damaging effects of air pollution. Chest. 2019;155:409-16.

2. Pedersen M, Stayner L, Slama R, Sorensen M, Figueras F, Nieuwenhuijsen MJ, et al. Ambient air pollution and pregnancyinduced hypertensive disorders: a systematic review and metaanalysis. Hypertension. 2014;64:494-500.

3. Ibrahimou B, Salihu HM, Aliyu MH, Anozie C. Risk of preeclampsia from exposure to particulate matter $\left(\mathrm{PM}_{2.5}\right)$ speciation chemicals during pregnancy. J Occup Environ Med. 2014;56: 1228-34.

4. Ibrahimou B, Albatineh AN, Salihu HM, Gasana J. Ambient $\mathrm{PM}_{2.5}$ aluminum and elemental carbon and placental abruption morbidity. J Occup Environ Med. 2017;59:148-53.

5. Ananth CV, Kioumourtzoglou MA, Huang Y, Ross Z, Friedman AM, Williams MA, et al. Exposures to air pollution and risk of acute-onset placental abruption: a case-crossover study. Epidemiology. 2018;29:631-8.

6. Shah PS, Balkhair T. Air pollution and birth outcomes: a systematic review. Environ Int. 2011;37:498-516.

7. Tapia VL, Vasquez BV, Vu B, Liu Y, Steenland K, Gonzales GF. Association between maternal exposure to particulate matter $\left(\mathrm{PM}_{2.5}\right)$ and adverse pregnancy outcomes in Lima, Peru. J Expo Sci Environ Epidemiol. 2020;30:689-97.

8. Siddika N, Balogun HA, Amegah AK, Jaakkola JJ. Prenatal ambient air pollution exposure and the risk of stillbirth: systematic review and meta-analysis of the empirical evidence. Occup Environ Med. 2016;73:573-81.

9. United States Environmental Protection Agency. Integrated Science Assessment (ISA) for Particulate Matter 2019. https://www. epa.gov/isa/integrated-science-assessment-isa-particulate-matter. Accessed 4 Dec 2020.

10. Tarrade A, Panchenko P, Junien C, Gabory A. Placental contribution to nutritional programming of health and diseases: epigenetics and sexual dimorphism. J Exp Biol. 2015;218(Pt 1):50-8.

11. Kroener L, Wang ET, Pisarska MD. Predisposing factors to abnormal first trimester placentation and the impact on fetal outcomes. Semin Reprod Med. 2016;34:27-35.

12. Gris J-C, Bouvier S, Cochery-Nouvellon É, Mercier É, Mousty È, Pérez-Martin A. The role of haemostasis in placenta-mediated complications. Thromb Res. 2019;181:S10-14.

13. Rodger MA, Gris J-C, de Vries JIP, Martinelli I, Rey É, Schleussner E, et al. Low-molecular-weight heparin and recurrent placenta-mediated pregnancy complications: a meta-analysis of individual patient data from randomised controlled trials. Lancet. 2016;388:2629-41.

14. United States Environmental Protection Agency. Integrated science assessment for ozone and related photochemical oxidants 2020. https://www.epa.gov/isa/integrated-science-assessment-isaozone-and-related-photochemical-oxidants. Accessed 4 Dec 2020.

15. Tokyo Metropolitan Government. Statistics of Tokyo 2015. https://www.toukei.metro.tokyo.lg.jp/tnenkan/tn-eindex.htm. Accessed 4 Dec 2020.

16. Ministry of the Environment, Japan. Current status of air pollution, 2014. https://www.env.go.jp/air/osen/index.html. Accessed 4 Dec 2020.

17. Matsuda Y, Hayashi K, Shiozaki A, Kawamichi Y, Satoh S, Saito S. Comparison of risk factors for placental abruption and placenta previa: case-cohort study. J Obstet Gynaecol Res. 2011;37:538-46.

18. Hayashi K, Matsuda Y, Kawamichi Y, Shiozaki A, Saito S. Smoking during pregnancy increases risks of various obstetric 
complications: a case-cohort study of the Japan Perinatal Registry Network Database. J Epidemiol. 2011;21:61-6.

19. Yoshino A, Nakashima Y, Miyazaki K, Kato S, Suthawaree J, Shimo N, et al. Air quality diagnosis from comprehensive observations of total $\mathrm{OH}$ reactivity and reactive trace species in urban central Tokyo. Atmos Environ. 2012;49:51-9.

20. Ministry of the Environment, Japan. Measurement manural of fine particulate matter in ambient atmosphere. http://www.env.go.jp/a ir/osen/pm/ca/manual.html. Accessed 4 Dec 2020.

21. Saito S, Hoshi J, Ikemori F, Osada K. Comparison of watersoluble organic carbon in $\mathrm{PM}_{2.5}$ obtained by filter analysis and continuous dichotomous aerosol chemical speciation. J Jpn Soc Atmos Environ. 2020;55:150-8.

22. Itabashi K, Miura F, Uehara R, Nakamura Y. New Japanese neonatal anthropometric charts for gestational age at birth. Pediatr Int. 2014;56:702-8.

23. Watanabe K, Naruse K, Tanaka K, Metoki H, Suzuki Y. Outline of definition and classification of "pregnancy induced hypertension (PIH)". Hypertens Res Pregnancy. 2013;1:3-4.

24. Red-Horse K, Zhou Y, Genbacev O, Prakobphol A, Foulk R, McMaster M, et al. Trophoblast differentiation during embryo implantation and formation of the maternal-fetal interface. J Clin Invest. 2004;114:744-54.

25. Fang GC, Wu YS, Chou TY, Lee CZ. Organic carbon and elemental carbon in Asia: a review from 1996 to 2006. J Hazard Mater. 2008;150:231-7.

26. Fong KC, Di Q, Kloog I, Laden F, Coull BA, Koutrakis P, et al. Relative toxicities of major particulate matter constituents on birthweight in Massachusetts. Environ Epidemiol. 2019;3:e047.

27. Brauer M, Lencar C, Tamburic L, Koehoorn M, Demers P, Karr C. A cohort study of traffic-related air pollution impacts on birth outcomes. Environ Health Perspect. 2008;116:680-6.

28. Yamagami M, Ikemori F, Nakashima H, Hisatsune K, Osada K. Decreasing trend of elemental carbon concentration with changes in major sources at Mega city Nagoya, Central Japan. Atmos Environ. 2019;199:155-63.

29. Drwal E, Rak A, Gregoraszczuk EL. Review: polycyclic aromatic hydrocarbons (PAHs)-action on placental function and health risks in future life of newborns. Toxicology. 2019;411:133-42.

30. Basu R, Harris M, Sie L, Malig B, Broadwin R, Green R. Effects of fine particulate matter and its constituents on low birth weight among full-term infants in California. Environ Res. 2014;128:42-51.
31. Zhang R, Jing J, Tao J, Hsu SC, Wang G, Cao J, et al. Chemical characterization and source apportionment of $\mathrm{PM}_{2.5}$ in Beijing: seasonal perspective. Atmos Chem Phys. 2013;13: 7053-74.

32. Huppertz B. Placental origins of preeclampsia: challenging the current hypothesis. Hypertension. 2008;51:970-5.

33. Oyelese Y, Ananth CV. Placental abruption. Obstet Gynecol. 2006;108:1005-16.

34. Newby DE, Mannucci PM, Tell GS, Baccarelli AA, Brook RD, Donaldson K, et al. Expert position paper on air pollution and cardiovascular disease. Eur Heart J. 2015;36:83-93b.

35. Wu S, Deng F, Wei H, Huang J, Wang H, Shima M, et al. Chemical constituents of ambient particulate air pollution and biomarkers of inflammation, coagulation and homocysteine in healthy adults: a prospective panel study. Part Fibre Toxicol. 2012;9:49.

36. Ganguly P, Alam SF. Role of homocysteine in the development of cardiovascular disease. Nutr J. 2015;14:6.

37. Chaudhry SH, Taljaard M, MacFarlane AJ, Gaudet LM, Smith GN, Rodger M, et al. The role of maternal homocysteine concentration in placenta-mediated complications: findings from the Ottawa and Kingston birth cohort. BMC Pregnancy Childbirth. 2019;19:75.

38. Brucker N, Moro AM, Charao MF, Durgante J, Freitas F, Baierle $\mathrm{M}$, et al. Biomarkers of occupational exposure to air pollution, inflammation and oxidative damage in taxi drivers. Sci Total Environ. 2013;463-464:884-93.

39. Michikawa T, Morokuma S, Fukushima K, Ueda K, Takeuchi A, Kato K, et al. A register-based study of the association between air pollutants and hypertensive disorders in pregnancy among the Japanese population. Environ Res. 2015;142:644-50.

40. Sarnat SE, Klein M, Sarnat JA, Flanders WD, Waller LA, Mulholland JA, et al. An examination of exposure measurement error from air pollutant spatial variability in time-series studies. J Expo Sci Environ Epidemiol. 2010;20:135-46.

41. Bell ML, Belanger K. Review of research on residential mobility during pregnancy: consequences for assessment of prenatal environmental exposures. J Expo Sci Environ Epidemiol. 2012; 22:429-38.

42. Gray SC, Edwards SE, Schultz BD, Miranda ML. Assessing the impact of race, social factors and air pollution on birth outcomes: a population-based study. Environ Health. 2014;13:4. 